\title{
NOVA MÍDIA: AUTOPOIESE DA TECNOLOGIA E CO-EVOLUÇÃO SOCIAL
}

Gottfried Stockinger ${ }^{1}$

\section{INTRODUÇÃO}

Propomo-nos aqui a esboçar algumas hipóteses analíticas acerca da autopoiese do subsistema tecnológico que sustenta e formata a comunicação humana. Sob autopoiese entendemos a formação de um sistema aberto, autônomo, que se sustenta através da concatenação de suas próprias operações, no sentido dado por Niklas Luhmann a partir de fundamentos apresentados pelo biólogo chileno Humberto Maturana. ${ }^{2}$

Ou seja, perguntamos se as tecnologias de comunicação são meras extensões do homem, como McLuhan (1969) sugeriu; ou se se trata, em certas circunstâncias, de dispositivos independentes que formam sistemas de sentido auto-organizados. E, se for, quais seriam estas circunstâncias que possibilitariam tal transferência da capacidade de produção de sentido para a um dispositivo técnico? Será que, por exemplo, o computador em relação a Web-arte seria como o pincel em relação a um quadro de tela? As tecnologias ditas "novas", como o computador e a Web, fariam diferença quando se trata da avaliação do papel do homem e da máquina no processo comunicativo, ou enquanto mídia?

1 O autor é $\mathrm{PhD}$ pela Universidade Viena, Áustria, sociólogo e teórico da comunicação. Trabalhou no Brasil como Professor da UFPa - Dep. Sociologia, na UFBa - Facom - Programa de PósGraduação em Comunicação e cultura contemporâneas, atualmente na Universidade Tuiuti do Paraná, Mestrado em Comunicação e Linguagens. Faz parte do grupo de pesquisa sistêmica "Unified Theory of Information”, na Universidade de Tecnologia, Viena. Autor de vários livros, o mais recente em português "A Sociedade da comunicação - o contributo de Niklas Luhmann".

2 Para detalhes ver Stockinger (2003). 
Ainda que McLuhan em op. cit. aborde os meios técnicos de comunicação como extensões do aparelho sensório do ser humano, ele deixa entrever, na mesma obra, que em certas circunstâncias esses meios ganham "autonomia". Em suas próprias palavras, "com o advento da tecnologia elétrica, o homem prolongou, ou projetou para fora de si mesmo, um modelo vivo do próprio sistema nervoso central. Nesta medida, tratase de um desenvolvimento que sugere uma auto-amputação desesperada e suicida, como se o sistema nervoso central não mais pudesse contar com os órgãos do corpo para a função de amortecedores de proteção contra as pedras e as flechas do mecanismo adverso. (McLuhan, 1969, p. 61).

Assim, os meios de comunicação aparecem como mensageiros devido a sua própria natureza de medium, o que levou McLuhan a afirmar que "o meio é a mensagem”. Ora, se o medium produz significados por sí próprio, fica difícil tratá-lo como mera ferramenta ou "suporte".

Com o processamento automático de mensagens pelos dispositivos eletrônicos, nomeadamente pela Web, se abriu o caminho para a criação de uma inteligência comunicativa artificial que merece ser observada sob o ponto de vista de sua autopoiese enquanto sistema autônomo. Como tal, ele passa a ser um "participante" de processos de comunicação humana, tanto no sentido de fazer parte do sistema homem-máquina, híbrido, como no sentido de constituir uma parte autônoma, auto-organizada, que se defronta com o ser humano, horizontalmente, como "parceiro" de comunicação.

Mas, a primeira vista fica igualmente difícil acreditar numa autopoiese dos sistemas e meios técnicos de comunicação, sobretudo quando usamos o conceito no seu sentido amplo. Mas mesmo limitando o conceito de meio de comunicação aos dispositivos eletrônicos e interativos, no sentido estrito, a reposta há de ser ponderada. Há de se perguntar se existem hoje em dia ambientes técnicos suficientemente maduros para poder permitir a autopoiese do sistema tecnológico de comunicação. Temos que nos perguntar sobre a qualidade da interação entre o ser humano e 0 computador. Jogamos contra ele, xadrez, por exemplo, e ele nos responde com lances aparentemente inteligentes. Já faz alguns anos que surgiu o Deep Blue, o primeiro computador ganhar um jogo contra o então campeão mundial da disciplina, o russo Garry Kasparov. 
No entanto, para completar estas considerações ainda há de inverter a questão macluhaniana: podemos perguntar até que ponto não foi o próprio homem a tornar-se mera extensão dos meios de comunicação, sendo "escravizado" pela "máquina de comunicação", que lhe indoutrina e de cujos efeitos na sua vida ele não escapa.

Finalmente há de considerar ainda uma terceira hipótese, a de ver homem e meios integrados num "ser" híbrido único. Aliás, é sobremaneira atrativo de resolver o dilema mcluhaniano e perceber os sistemas sociais usuários de tecnologia de comunicação como construções híbridas. Estas seriam caraterizados pela interação homem - máquina, que resulta num produto tipo cyborg, onde a hibridez desta figura the atribui um senso construido por Inteligencia Artificial (IA), ou seja um ser sui generis. Esta IA estaria embutida no próprio dispositivo técnico, mas também permite combinações estáveis com a inteligencia humana, criando assim um conjunto "técnico", de criatividade própria.

Resumindo, ficamos assim com 3 pontos de vista possíveis:

1)Os meios e suas mensagens como extensão do (pensamento e do agir do) homem

2)O (pensamento e o agir do) homem como extensão dos meios aos quais está exposto.

3)Uma combinação de ambas as hipóteses, onde se vê o homem e os seus meios de comunicação numa combinação híbrida que permita sua união e/ou interação.

\section{NOVAS TECNOLOGIAS - VELHO EFEITO? - UM EXEMPLO DA FOTOGRAFIA DIGITAL}

Para avaliar o efeito das novas tecnologias há de refletir primeiro sobre as condições contemporâneas de reprodução do sistema social em relação a sua dependência e/ou independência dos meios técnicos / tecnológicos e energéticos de maneira geral, e dos meios de comunicação em particular.

Quanto a isso não pode haver dúvida de que a sociedade complexa da atualidade seria impossível de se sustentar se não pudesse dispor desses 
meios em questão. Sabemos que uma simples falta de energia elétrica por uma período não muito curto paralisa não só a economia como também a vida social, em grande parte baseado em divertimento, campo onde reina a tecnologia de comunicação, com seus vários suportes, que aliás não se deixam separar das mensagens por eles expressas.

Para analisar melhor nossa hipótese de uma possível transição do paradigma mcluhaniano, dos meios como extensão, para um paradigma da possível autopoiese desses meios, tomemos primeiro o exemplo a fotografia. Olharemos como os avanços tecnológicos, nomeadamente o da fotografia digital, permitem ou não um tratamento diferenciado por sistemas homemmáquina, que leva a uma combinação genuina da forma industrial e da forma informacional da fotoimagem.

\section{Case A: 0 poder da fotografia digital}

Ondino ligou o computador para "revelar" as fotos que ele tirou na festa. Chamou o programa próprio e fez o download para visualização das imagens na tela de 17 polegadas. Naquela festa ele tinha chegado a conhecer Anita, dançou e conversou com ela, e agora estava curioso em ver o retrato dela. Essa foto sim, essa aí, não nessa não, foi naquela que dá para ver, claramente, que ela sorriu para ele. Não apenas um sorriso de Mona Lisa, do qual não se sabe se é ou não. Ou será que o riso foi apenas para a objetiva da câmera, a qual ele segurava com as duas mãos na altura do peito, olhando pelo visor digital que estava virado para cima? Como a foto digital era de alta resolução, ela permitiu que ele zoomasse o rosto dela até chegar ao recorte facial de Anita, que permitisse, com mais um zoom, mostrar exatamente o conjunto olhos - lábios. A partir daí bastava processar a imagem até poder tirar o teima. Dito, feito. Em alta resolução deu agora para perceber com facilidade, que o olhar dela estava direcionado, e sem dúvida, que os lábios ensaiaram um gesto de beijo. Tanto nesta como também em outras fotos. Foi neste momento que se confirmou o que antes parecia mera suposição. E assim se iniciou uma relação, da qual não sabemos se foi feliz e se durou para sempre.

O case demonstra como a entrada da nova tecnologia fotográfica modificou as possibilidades da percepção humana, modificação esta que tem consequências sociais e psicológicas efetivas? 
A pergunta é traiçoeira, porque aparentemente foi a tecnologia nova que permitiu descobrir o fenômeno. Aqui nos deparamos com um caso em que, aparentemente, a nova teconologia teria contribuido para uma mudança de percepção. No entanto, há aqui equivalências funcionais entre 0 analógico e o digital. Ondino poderia ter usado um filme com sensibilidade ótica mais elevada, de 400 ASA por exemplo, ou mais, até alcançar as mesmas possibilidades de "zoomar" a imagem, na hora da revelação da foto.

No case exposto, a máquina fotográfica em si ainda não esgota as possibilidades da mídia digital. Ela opera em "modo antigo",no case, apenas permitindo a melhora da resolução.

Efetivamente poderemos imaginar o case construido de uma forma que permite a mídia digital operar em "modo novo". Poderiamos imaginar um amigo do Ondino manipulando a foto de tal forma que a moça apareça sorrindo para ele. Ou poderiamos introduzir, em vez do amigo, um computador, cujo programa opera a transformação automaticamente. $\mathrm{Ou}$ seja, poderia haver uma transformação da imagem digital com programas que vão além do tratamento da imagem de película, analógica, embora haja possibilidades de retoque mesmo em fotos de película.

\section{O PROCESSAMENTO DA IMAGEM}

Ao aumentar assim, gradualmente, a sofisticação tecnológica, chega-se a passar o horizonte para além da fronteira entre os meios como extensão (maquina fotografica) e os meios de criação autopoiética (programa de processamento de imagens). Há momentos na história quando esta fronteira se abre e a introdução de novas tecnologias de percepção leva a uma transformação tanto da percepção como do processamento das imagens. Foi o que ocorreu por exemplo a partir do uso do telescópio e do microscópio.

O primeiro produziu o desencanto de que "lá em cima" estaria outro mundo, chamado de "céu", quando na verdade se viu que "lá em cima" havia também matéria, e bem parecida com aquela da terra. E o microscópio revelou que aquilo que parecia sólido e imutável está na verdade cheio de vida e movimento. Este incremento na nítidez e resolução da percepção 
(fatores técnicos) levaram a toda uma mudança dos paradigmas de então (fatores socio-psíquicos).

Sempre que uma nova tecnologia de midia é introduzida, aumentam e se multiplicam as formas de percepção humana e se diferenciam os seus formatos. O próprio fato de alguém ter acesso a fatos e eventos antes não percebíveis (pôr exemplo à olho nu) abre a possibilidade de alargar a realidade. $\mathrm{O}$ case $\mathrm{A}$, analisado acima, já mostra isso.

A questão é se se trata de uma alargamento meramente "quantitativo", ou seja de uma melhoria na resolução, velocidade de tratamento, ou outro parámetro mensurável em moldes lineares; ou se se trata de um aprofundamento ou elevação a um novo patamar de percepção que permita novas formas de manipulação e processamento da imagem. Um exemplo de transição para uma nova qualidade, baseada em quantidade aumentada, é a passagem da foto para o filme, que é foto em movimento, mas não só. $\mathrm{O}$ acréscimo do movimento requer novas formas estéticas, socialmente reconhecidas e permitidas.

Novas formas de processamento correspondem também a novos formatos sociais de sua produção e recepção. O que está escrito em jornais ganha ainda mais força de ser "verdadeiro" quando é acompanhado por fotos, ou quando é repetido por outras mídias, de formatos mais diferenciados de processamento da imagem, como por exemplo a TV. A mídia, no seu conjunto e na sua coerência faz com que a notícia vire fato. $\mathrm{Na}$ sua co-evolução com a o saber e a consciência pública, a mídia consegue coisificar uma realidade virtual, que corresponde a uma realidade externa, co-criada pelo medium.

Ora, se tal realidade posta por processamento de texto e imagens se afasta de sua base antes tida como um construto "real", ela entra e se concentra no mundo do imaginário, enquanto realidade virtual que tem como base uma experiência mediática. E é nisso que ela coincide com a realidade coisificada pela mídia, e é atraves disso que ela não escapa da avaliação como sendo um produto tão real quanto as coisas da natureza o são, mesmo que não seja tangível. Trata-se de uma "segunda natureza", artificial, formada conforme os preceitos humanos, e filtrados pelas possibilidades tecnológicas do momento em que é produzido. 


\section{A CO-EVOLUÇÃO DOS SISTEMAS TECNOLÓGICO E HUMANO}

Num contexto de segunda natureza, estruturada em cultura e produzida em processos de comunicação, qual o grau de realidade ou 0 grau de mera imaginação? De uma realidade processada em forma de informação, em forma de imagens e símbolos manipulados?

Na verdade é o próprio desenvolvimento dos meios de comunicação que deixa sempre espaço para mais desenvolvimento, para mais perfeição no processamento. "Assim como o filme silencioso reclamava o som, o filme sonoro reclama a cor", dizia Serguei Eisenstein. ${ }^{3}$

Se olharmos para a imagem fotográfica ou cinematográfica, a proximidade com uma representação de algo real pode ser uma perspectiva ou um critério de avaliação. E este anseio de ficar próximo do real foi e ainda é expressivo; o desejo de retirar a fronteira entre o virtual e o real está iminente em todos os esforços tecnológicos da nova mídia. Que o artificial pareça natural! Mas, ao mesmo tempo o homem quer aproximar a imagem, ao máximo, à realidade "natural" (mesmo que esta seja uma segunda natureza). Há este desejo de que, uma vez alcançado uma aproximação suficiente, poder manipular e processar a imagem, já de novo se afastando da realidade "natural", abrindo o mundo da abstração, da ficção e dos efeitos visuais.

O impacto da tecnologia em si não seria suficiente. Há por detrás dos novos formatos de processamento da imagem uma gama de questões psicossociais que pressionam e estressam os usuários e suas organizações que usam a tecnologia. Trata-se de fatores que funcionam como gatilho de um desenvolvimento de linguagens e formas sociais através de e em ambientes virtuais, como por exemplo a fotografia. Estes ambientes permitem a compactação do espaço e do tempo para dimensões de observação humana. Quer dizer que o processamento da imagem não tem seus limites apenas no tecnicamente possível, mas também no pessoalmente e no socialmente admissível!

\footnotetext{
3 Apud McLuhan(1969, p.67).
} 
A questão é até que ponto esse desenvolvimento leva a uma nova qualidade da mídia, nova no sentido de provocar percepções e sensações antes inéditas através de uma tecnologia que ou imita cada vez mais o real, ou consegue se afastar cada vez mais dele, por exemplo através de efeitos especiais. Tanto o aproximar-se como o afastar-se são tidos como aperfeiçoamento da mídia.

Se do ponto de vista do usuário a nova mídia causa "impacto", do ponto de vista da mídia o usuário é "apenas" fornecedor de energia (em forma de informação) para o sistema técnico, que usa essa informação para reproduzir a sua vida sui generis. Ou seja, ele usa os esforços do usuário para sua autopoiese. Ambos, sistema humano e sistema tecnológico coevoluem, isto é que tanto a rede (técnica) evolui como ambiente-meio das atividades sensórias do homem, enquanto este evolui por poder se erguer além das suas limitações biológicas.

Uma exemplificação deste tipo de co-evolução é dada no filme 2001 - Odisséia no espaço, dirigido por Stanley Kubrick (1970).

\section{Case B: A odisséia da inteligência humana e artificial}

O filme "2001 - Odisséia no espaço" parece apresentar três formas de inteligência comunicativa, que interagem enquanto sistemas autoorganizados:

1 - Uma inteligência humana, que emerge, na "aurora da humanidade", baseado no uso de instrumentos, como extensão do corpo humano. Ela comunica a seu ambiente o uso de instrumentos e ferramentas para fins pacíficos ou bélicos. No filme, tal acordar da consciência de dominação é representada pelos macacos que descobrem a função técnica de ossos de feras mortas, para serem usadas como armas para caça e defesa. Será esta mesma forma de inteligência comunicativa que guiará o homo sapiens na era teconológica, sendo que o filme o mostra utilizando naves espaciais e explorando o universo fora do sistema solar.

2- Uma segunda forma de inteligencia, artificial, de poder comunicativo próprio, mostra-se na gestalt do computador H.A.L., nome formado pelas letras que seguem as letras I.B.M. no alfabeto. 
Sua inteligência digital movido por um fluxo constante de energia (elétrica) que aciona o sistema de (auto-)programação lhe permite um processo de autopoiese, chegando a evoluir de forma autônoma, e levando-o a interagir e até a se opor ao comando dos seus criadores humanos.

3- Finalmente uma forma mais transcendental de inteligência se faz presente e se "anuncia" na forma de dois monólitos negros, representando uma consciência universal, cósmica e extraterrestre, que interage e se comunica de forma mística com os seres no seu ambiente, no caso macacos e homens.

Em comparação e relação com os monólitos negros, as outras duas formas de inteligência se igualam, ambas são "construções" e ambas se condicionam mutuamente, ambas interdependem dentro de sistemas sociotécnicos "híbridos", na atualidade.

Já que os monólitos representam uma força inexplicável (mesmo no filme ela fica inexplicada, por ser inexplicável, mística), o sistema humano e o sistema automático são os mais interessantes. Para tal devem ser pensados na sua interação, por sua vez fundada na interdependência mencionada.

Poder-se-ia dizer que tal interdependência é apenas fictícia, porque 0 ser humano pode simplesmente desligar o computador, apagar sua memória (como foi o caso com o HAL). Mas, ao proceder assim, o homem desliga também toda uma infraestrutura técnica, já largamente indispensável para a vida biológica e social. A interdependência passou a ser, portanto, algo real.

Pode-se argumentar que já no mom do osso transformado em ferramenta tal dependência se verifica. Acostumado a caçar, de lá em diante, com instrumentos e armas apropriados, o homem não voltou mais ao estágio da caça á mão desarmada.

Não está, portanto, aí a diferença entre a inteligência comunicativa que encontramos na invenção da ferramenta óssea e aquela encontrada na criação do computador conectado em rede com o ser humano. A diferença está na extensão mecância da ferramenta, e na "extensão" não linear do computador. A ferramenta não faz nada enquanto não estiver sendo usada pelo homem. O computador em rede poderá "trabalhar" e sobretudo 
“aprender”, sem ser tocado por mão humana. Aprender quer dizer tirar conclusões de eventos anteriores, ou seja reagir de forma complexa, a fim de poder interagir com o ser humano. Senão vejamos:

\section{Case C: A vitória de Deep Blue}

No dia 4 de Maio de 1997 o computador Deep Blue venceu o campeão mundial de xadrez, o Russo Garry Kasparov. Foi a primeira vitória de um cérebro eletrônico sobre um cérebro humano, na disciplina. O New York Times comentou: "O problema para Kasparov foi que Deep Blue não mostrou fraquezas. Ele segurou a vantagem de iniciar o jogo, já que jogou com as peças brancas, iniciando pacientemente com uma abertura conhecida como Ruy Lopez, e na fase final pressionou o rei de Kasparov com ameaças de torre e rainha, nunca o deixando respirar."

Um crítico da área da Inteligência Artificial comentou, no mesmo jornal: "A IBM escreveu um programa excelente para jogar xadrez. Mas a máquina não sabe que ela joga xadrez. Ela não têm um modelo de sí próprio enquanto programa. Quando ela vence, ela não sabe porque. Nós precisamos de computadores que sabem compreender ciência de computação. Isso é que seria a verdadeira Inteligencia Artificial.”

A máquina é aqui tratada como um ser humano, sendo que o crítico ainda exige do autómato ainda mais qualidades do que as já exibidas. A máquina aparece sem "fraquezas", com "paciência”, exercendo "pressão psicológica”, sem "deixar respirar" o adversário. Tais qualidades são comunicadas sem que o relato entre em contradição com aquilo que "realmente" ocorreu. Mesmo que o sistema "psicológico" do Deep Blue fique escondido na sua caixa preta, a atribuição de qualidades humanas - ou melhor: a sua programação - é suficiente para a comunicação o tratar como "ser".

Como a máquina, para saber jogar e, mais ainda, se sobrepor, necessita de interagir - agir e reagir - "adequadamente", ela precisa saber "aprender” não apenas antes do jogo. A sua programação deve permitir fluxos e refluxos circulares de informação para poder responder a uma determinada situação com um determinado comportamento, durante 0 jogo!. Pelas regras, a máquina não podia ser reprogramada durante o jogo, 
após cada lance. Ela tinha que obedecer certas regras de autopoiese, que lhe dava a "autonomia de vôo" durante o jogo.

Por mais dúvidas que se possa ter acerca do experimento, não pode haver dúvida de que a interação máquina - ser humano é levada a um ponto crítico, onde o sistema tecnológico aparece com um alto grau de autopoiese construtiva.

Assim, a mudança de paradigma a ser encarada se espelha na transição de máquinas-extensões para máquinas auto-organizadas, automáticas, de base inteligente própria, cuja programação se assemelha mais a um ensinar e aprender do que um simples comandar, linha por linha.

Mas, a "chamada tecnologia de comunicação não é já, por ela mesma, comunicativa. As vias e os acessos permitem, mas não obrigam, a comunicarse. Apenas quando o usuário conecta com outros, quando carrega sites, imagens, quando emite e recebe e-mails, clica num hiperlink etc., apenas nestes momentos, o medium se torna um sistema social para ele, e ele passa a ser um dos seus criadores e reprodutores. Neste momento, a questão se torna mais complexa. Ela toca no impacto sociológico e comunicativo da rede técnica." (Stockinger, 2003, p. 186).

A máquina mecânica não aprende, enquanto o robôt tem sensores para se adaptar a diversos ambientes. Esta qualidade de adaptação exige poderes de auto-transformação, qualidade essa atribuida, até agora, apenas a seres biológicos.

\section{REFERÊNCIAS}

IRON, Robert. "Deep Blue: inspires deep thinking about artificial intelligence by computer scientists", in Currents, UCSC http://www.ucsc. edu/oncampus/currents/97-05-05/chess.htm, 1997.

McLUHAN. Marshall, Os meios de comunicação como extensão do homem (Understanding media). São Paulo: Cultrix, 1969.

STOCKINGER, Gottfried. A sociedade da comunicação: $o$ contributo de Niklas Luhmann. Rio de Janeiro: PapelVirtual, 2003. 
